\title{
On the choice of methodology for evaluating dose-rate effects on radiation-related cancer risks
}

\author{
Linda Walsh ${ }^{1}$ (1) $\cdot$ Roy Shore $^{2}$ (i) $\cdot$ Tamara V. Azizova $^{3}$ (i) $\cdot$ Werner Rühm ${ }^{4}(1)$
}

Received: 13 May 2021 / Accepted: 17 June 2021 / Published online: 25 June 2021

(c) The Author(s) 2021

\begin{abstract}
Recently, several compilations of individual radiation epidemiology study results have aimed to obtain direct evidence on the magnitudes of dose-rate effects on radiation-related cancer risks. These compilations have relied on meta-analyses of ratios of risks from low dose-rate studies and matched risks from the solid cancer Excess Relative Risk models fitted to the acutely exposed Japanese A-bomb cohort. The purpose here is to demonstrate how choices of methodology for evaluating dose-rate effects on radiation-related cancer risks may influence the results reported for dose-rate effects. The current analysis is intended to address methodological issues and does not imply that the authors recommend a particular value for the dose and dose-rate effectiveness factor. A set of 22 results from one recent published study has been adopted here as a test set of data for applying the many different methods described here, that nearly all produced highly consistent results. Some recently voiced concerns, involving the recalling of the well-known theoretical point- the ratio of two normal random variables has a theoretically unbounded variance - that could potentially cause issues, are shown to be unfounded when aimed at the published work cited and examined in detail here. In the calculation of dose-rate effects for radiation protection purposes, it is recommended that meta-estimators should retain the full epidemiological and dosimetric matching information between the risks from the individual low dose-rate studies and the acutely exposed A-bomb cohort and that a regression approach can be considered as a useful alternative to current approaches.
\end{abstract}

Keywords Dose-rate effects $\cdot$ Meta-analysis $\cdot$ Radiation cancer risk

Linda Walsh

linda.walsh@uzh.ch

Roy Shore

hrshore@gmail.com

Tamara V. Azizova

clinic@subi.su

Werner Rühm

werner.ruehm@helmholtz-muenchen.de

1 Department of Physics, Science Faculty, University of Zürich, Winterthurerstrasse 190, 8057 Zürich, Switzerland

2 Department of Population Health, New York University Grossman School of Medicine, New York, USA

3 Southern Urals Biophysics Institute, Ozyorskoe shosse 19, Ozyorsk, Chelyabinsk region 456780, Russia

4 Institute of Radiation Medicine, Helmholtz Zentrum München- German Research Center for Environmental Health, 85764 Neuherberg, Germany

\section{Introduction}

Many studies on radiation-related detrimental health effects rely on collecting results from published papers with the aim of providing compiled information to guide radiation protection. Information on how dose-rate effects may influence radiation-related cancer risks may be compiled from many modern radiation epidemiology studies. Such compilations of individual study results may be combined to provide evidence of whether or not the cancer risk per unit dose of chronic exposures accumulated over an extended period of time differs noticeably from the cancer risk per unit dose from a single acute exposure. The dose and dose-rate effectiveness factor (DDREF) concept (ICRP 1991) provides a general estimate of the ratio of cancer risk per unit of acute exposure to the cancer risk per unit of chronic exposure while concurrently aiming to provide estimates of extrapolation from high to low doses. DDREF is a radiation protection concept and may be interpreted as a combination of a lowdose effectiveness factor (LDEF) to extrapolate from high 
to low doses, and a dose-rate effectiveness factor (DREF) to extrapolate from high to low dose rates. In the currently recommended dose limits for occupational exposures (ICRP 2007), the assumption is that solid cancer risk factors are a factor of two lower than for the A-bomb survivors (i.e., DDREF $=2.0$ ). However, ICRP is currently reviewing the usefulness of this concept and the weight of evidence for various numerical values of estimates for DDREF (Rühm et al. 2015, 2016; Shore et al. 2017).

Recently, several compilations of individual study results have aimed to obtain direct evidence on the magnitudes of the DREF. The purpose here is not to review all such studies, but rather to demonstrate how choices of methodology for evaluating dose-rate effects on radiation-related cancer risks may influence the DREF results reported. Two recent compilations, Jacob et al. (2009), Shore et al. (2017), applying very similar methodology, have been well cited and attracted positive feedback. However, concern also has been raised that the methods used in deriving the DREF results might require improvement (Little et al. 2021). A key concern about the methods is a well-known theoretical point (Stuart and Ord 1994): the ratio of two normal random variables has a theoretically unbounded variance, which in certain circumstances could yield practical inconsistencies in calculated variances, if this is not accounted for in a practical way. This could potentially be relevant, because the two studies, Jacob et al. (2009), Shore et al. (2017), produced meta-analysis estimates involving ratios of Excess Relative Risks (ERR), assumed to be normally distributed, as estimators of the DREF. The current authors were directly involved in either one or both of these studies and are well placed to examine how choices of methodology may influence evaluations of dose-rate effects on radiation-related cancer risks. A set of results from the paper by Shore et al. (2017) has been adopted here as a test set of data for applying different methods to explore this theoretical issue. In addition, many other meta-analysis methods were employed in work done for the Shore et al. (2017) paper, though not originally reported are now reported here, along with newly applied methods, to investigate further if there were any potential issues with the original choice of methodology used in Jacob et al. (2009), Shore et al. (2017).

\section{Materials and methods}

\section{Methods originally applied in the two studies by Jacob et al. (2009), Shore et al. (2017)}

The methods that were applied in the two studies of Jacob et al. (2009) and Shore et al. (2017) have been given already in detail in these papers. However, for completeness, they are summarized here. A comprehensive list of human radiation epidemiology studies with dose-response analyses of low dose-rate solid cancer data was compiled by literature review. For each low dose-rate study that was included in the meta-analysis, the published solid cancer excess relative risk (ERR) per Gy and the confidence interval (CI) were obtained directly from the publications. For each low doserate study included, a carefully matched ERR was calculated from the solid cancer ERR models fitted to the A-bomb Life Span Study (LSS) cohort. The matching was done on age-attained, age at exposure, sex proportion, incidence or mortality, solid cancer outcome type, and dose type, using the full LSS datasets and re-optimizing the LSS relevant models to be centered at the matched covariable values. Of particular note here is that no LSS sub-sets of data were used for this purpose, but the full cohort data (even the sex proportion was matched by applying weighted sex modifiers in the re-optimized LSS model). Then, the ratio of the ERR in low dose-rate cohorts to the ERR in the A-bomb Life Span Study (LSS) cohort was computed and the standard error of the ratio obtained by the standard method of Gaussian propagation of errors (Bevington and Robinson 2003) in Shore et al. (2017) and by simulation in Jacob et al. (2009) (but the simulation results were also confirmed with propagation of errors). The Gaussian propagation of errors method is also known as the Delta-method because of the application of derivatives and this latter terminology is applied hereafter.

The pooled, inverse-variance weighted mean ratio, $Q$, was calculated from the $q_{i}$ study to LSS ERR estimates from all individual $i$ studies (Table 1) under the basic premise that the average estimate calculated for the pooled study results is a better estimate than those provided by any of the individual studies. The variance of each $\mathrm{q}_{\mathrm{i}}$ ratio was calculated from standard errors using the Delta-method and meta-analyses were done both with and without the assumption of heterogeneity of risk ratios (Sutton and Higgins 2008). Cochran's $Q$ statistic (and corresponding p value) method was applied to test for heterogeneity among study risk estimates and the DerSimonian-Laird method (DerSimonian and Laird 1986) was applied to account for heterogeneity between studies and for obtaining the overall variance on $Q$.

\section{Further methods applied here}

Two further methods as suggested, for example, by Beyene et al. (2005), for error estimation of a ratio parameter are applied here. The first method is the Fieller's method (Fieller 1940) as a generic approach for a ratio parameter and this method was also suggested for this type of application by Little et al. (2021). The second method is the generalized linear modeling framework (McCullagh and Nelder 1989), considered here in the form of York regression (York 2004), which provides a basis for a useful re-parameterization of the current meta-analysis problem. 
Table 1 Results for the excess relative risk (ERR) ratio, $\mathrm{q}_{\mathrm{i}}$, the ratio of the individual study ERR/unit dose to matched LSS ERR/unit dose, and the standard error of $\mathrm{q}_{\mathrm{i}}$, obtained with two different meth-

\begin{tabular}{|c|c|c|c|c|c|c|c|}
\hline \multicolumn{3}{|l|}{ Low dose-rate study } & \multicolumn{2}{|l|}{ LSS } & \multicolumn{3}{|c|}{ Combined estimates } \\
\hline Cohort and reference & ERR/Gy & Std. Err & ERR/Gy & Std. Err & $\begin{array}{l}\text { ERR ratio } \\
\left(q_{i}\right) \text { (study/ } \\
\text { LSS) }\end{array}$ & $\begin{array}{l}\text { Std. Err } \\
\text { Delta method }\end{array}$ & $\begin{array}{l}\text { Std. Err } \\
\text { Fieller's method }\end{array}$ \\
\hline $\begin{array}{l}\text { France, UK, US nuclear workers (Richardson et al. } \\
\text { 2015) }\end{array}$ & 0.47 & 0.185 & 0.3538 & 0.058 & 1.328 & 0.567 & 0.569 \\
\hline Japan nuclear workers (Akiba et al. 2012) & 0.20 & 0.895 & 0.4551 & 0.144 & 0.439 & 1.972 & 1.998 \\
\hline Chernobyl liquidators (Kashcheev et al. 2015) & 0.58 & 0.318 & 0.2282 & 0.056 & 2.542 & 1.529 & 1.543 \\
\hline Techa River (Schonfeld et al. 2013) & 0.61 & 0.314 & 0.5288 & 0.056 & 1.154 & 0.606 & 0.607 \\
\hline Mayak workers (Sokolnikov 2015) & 0.12 & 0.046 & 0.4271 & 0.066 & 0.281 & 0.116 & 0.116 \\
\hline Yangjiang high natural background (Tao et al. 2012) & 0.19 & 1.253 & 0.4904 & 0.071 & 0.387 & 2.555 & 2.562 \\
\hline Rocketdyne (Boice et al. 2011) & -0.20 & 0.893 & 0.2298 & 0.037 & -0.870 & 3.888 & 3.902 \\
\hline German U millers (Kreuzer et al. 2015) & 0.27 & 1.419 & 0.3554 & 0.061 & 0.747 & 3.994 & 4.009 \\
\hline $\begin{array}{l}\text { US nuclear power plant workers (Cardis et al. 2007; } \\
\text { Howe et al. 2004) }\end{array}$ & 0.51 & 1.696 & 0.4459 & 0.098 & 1.135 & 3.813 & 3.837 \\
\hline Canada nuclear workers (Zablotska et al. 2014) & -1.20 & 1.832 & 0.3555 & 0.081 & -3.376 & 5.210 & 5.247 \\
\hline Port Hope (Zablotska et al. 2013) & 0.12 & 0.439 & 0.2696 & 0.043 & 0.445 & 1.629 & 1.635 \\
\hline Sweden nuclear facilities (Cardis et al. 2007) & -0.58 & 4.298 & 0.339 & 0.074 & -1.711 & 12.685 & 12.763 \\
\hline $\begin{array}{l}\text { German nuclear power plant workers (Merzenich et al. } \\
\text { 2014) }\end{array}$ & -1.02 & 1.551 & 0.3182 & 0.076 & -3.207 & 4.934 & 4.971 \\
\hline Rocky Flats Plutonium facilities (Cardis et al. 1995) & -1.63 & 1.295 & 0.2847 & 0.067 & -5.725 & 4.745 & 4.782 \\
\hline $\begin{array}{l}\text { Belgian nuclear workers (Cardis et al. 2007; Engels } \\
\text { et al. 2005) }\end{array}$ & -0.59 & 4.152 & 0.3515 & 0.079 & -1.679 & 11.819 & 11.897 \\
\hline $\begin{array}{l}\text { Finnish nuclear workers (Cardis et al. 2007; Auvinen } \\
\text { et al. 2002) }\end{array}$ & 174.00 & 544.729 & 0.3179 & 0.075 & 547.342 & 1718.319 & 1730.681 \\
\hline Spain nuclear facilities (Cardis et al. 2007) & 1.02 & 7.830 & 0.3393 & 0.077 & 3.006 & 23.088 & 23.244 \\
\hline $\begin{array}{l}\text { Australia nuclear workers (Cardis et al. 2007; Habib } \\
\text { et al. 2005) }\end{array}$ & 13.40 & 37.994 & 0.3835 & 0.076 & 34.941 & 99.315 & 99.833 \\
\hline Slovak nuclear workers (Gulis et al. 2003) & 9.50 & 24.516 & 0.4008 & 0.101 & 23.703 & 61.457 & 61.968 \\
\hline Kerala high natural background (Nair et al. 2009) & -0.13 & 0.265 & 0.336 & 0.059 & -0.387 & 0.793 & 0.796 \\
\hline Taiwan Co-60 contaminated flats (Hwang et al. 2008) & 0.30 & 0.395 & 1.243 & 0.172 & 0.241 & 0.320 & 0.321 \\
\hline Korea nuclear workers (Jeong et al. 2010) & 2.06 & 2.783 & 0.5575 & 0.113 & 3.695 & 5.048 & 5.075 \\
\hline
\end{tabular}

for the calculations, the full precision available from the literature or from re-fitting the LSS models was applied

The Fieller's method provides a novel way of expressing ratios as linear combinations of random variables and makes the computation of CIs or standard errors of ratios relatively simple, circumventing the theoretical issue of the ratio of two normal random variables having a theoretically unbounded variance. The full details are given in Fieller (1940), but for a modern description, suitable for swiftly understanding how to practically apply this method, and double checking the results via an inequality, see Beyene (2005). Details of the Fieller's method are also given in Little et al. (2021). The Fieller's method was applied here to obtain the standard errors and variances of each individual $\mathrm{q}_{\mathrm{i}}$ ratio that goes into the meta-analysis of individual risk ratios.

Generalized linear modeling is widely applicable in several different scenarios with different distributional ods, Delta method (Bevington and Robinson 2003) as originally applied in Shore et al. (2017), or Fieller's method (Fieller 1940) 


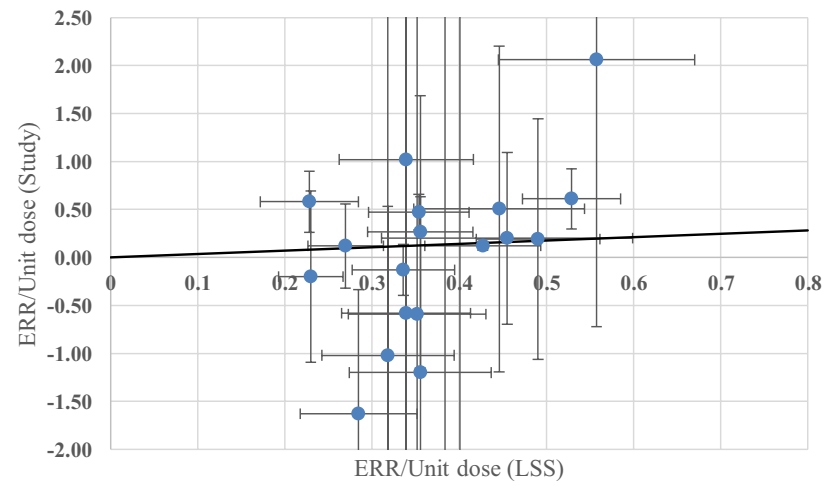

Fig. 1 Result of the meta-analysis reformulated as a York regression with the best fit (all studies, solid black line), which is also the same if calculated with orthogonal distance regression. Note that some of the off-scale points from Table 1 were omitted to obtain an illustrative scaling here, but these outlying points were included in the fit. The points are given with standard error bars

and one implemented in the Numerical Recipes subroutine called "fitexy" (Press et al. 1992). In addition, orthogonal distance regression (Boggs and Rogers 1990) was applied as an alternative method for checking the results with the SciPy implementation (Virtanen et al. 2020).

Meta-analytic methods for assessing risk heterogeneity are currently developing, so heterogeneity was also evaluated using the several other methods cited in the following publications (DerSimonian and Kacker 2007) and in Table 2. Here again, use was made of the open-source R-statistical programming language functions for all but one of the metaanalysis methods given in Table 2 in the metafor package (Viechtbauer 2010) and the metrology package was used for the remaining meta-analysis method (Paule and Mandel 1982).

\section{Test set of data for applying the further different methods}

The full set of risks from the paper by Shore et al. (2017) has been adopted here, as it was in Little et al. (2021), as a test set for applying the different methods to. This is the set of ERR estimates from the 22 low dose-rate studies and their corresponding 22 LSS ERR estimates from Table 2 of Shore et al. (2017) and all associated uncertainties.

\section{Results}

Table 1 gives the set of ERR estimates from the 22 low dose-rate studies and their corresponding 22 matched LSS ERR estimates from the Table 2 of Shore et al. (2017). The first column gives the low dose-rate study reference. Subsequent columns give: the ERR/unit dose for the low dose-rate study and the standard errors calculated from the published CIs; the ERR/unit dose from the matching LSS risk model central estimate and the standard errors obtained from the LSS model re-optimisations; the ratio of the two ERRs; the standard errors of the ratio calculated with the Delta method and the standard errors of the ratio calculated with Fieller's method. It can be seen from the two last columns of Table 1 that the choice of method is not critical here, because very similar results are obtained with both methods, generally only differing in the second or third decimal places of the estimated standard errors, a difference of $<0.6 \%$ on average and only two studies had as much as a $1 \%$ difference. It follows from this result that, since the meta-analysis methods are inverse-variance weighted, the individual study weightings will also be very similar from the two methods.

Table 2 gives the Meta-estimator of Q (the aggregated ratio of the study to LSS ERR risks) as originally reported by Shore et al. (2017) and as newly calculated here by various meta-analysis methods and also applying the meta-analysis reformulated as a York regression or an orthogonal distance regression with zero intercept. The Mayak study had a mean external dose (354 $\mathrm{mGy}$ colon dose) much higher than any of the other studies, so Table 2 shows the results with and without that study. The first four entries in Table 2 confirm that the choice of method between the Delta method and Fieller's method for calculating the standard errors of the ratios and therefore the weightings is not critical at all, because the $Q$ values are the same to three or four decimal places and the standard errors are very similar (for all studies included, 0.1040 with Fieller's method and 0.1036 with the Delta-method - a difference that would not usually be reported as noticeable in the literature which would normally only quote two decimal places here) and the standard errors are virtually identical. Specifically, the standard errors for Fieller's method and the Delta method differed by $0.4 \%$, $0.3 \%, 0.5 \%$, and $0.4 \%$ for all mortality and incidence $(\mathrm{M}+\mathrm{I})$ studies, all $\mathrm{M}+\mathrm{I}$ except Mayak, all $\mathrm{M}$ studies, and all $\mathrm{M}$ except Mayak, respectively. All other meta-analytic methods give consistent results except the Sidik-Jonkman estimator (Sidik and Jonkman 2005a, b) and the authors are currently investigating why this method gives different results. Table 2 also shows that York regression (York 2004) similarly produces results that are very close numerically to the various meta-analytic results. The best fitting line considering all studies, from York regression, which also corresponds to the line obtained with orthogonal distance regression, and most of the data points are shown in Fig. 1. 
Table 2 Results for $Q$ [the ratio of the study to LSS risks, i.e., the inverse of the dose-rate effectiveness factor (DREF)] and the standard error of $Q$, obtained with different methods

\begin{tabular}{|c|c|c|c|c|c|}
\hline Method 1 & Method 2 & $\begin{array}{l}\text { All studies } \\
\text { Estimated } Q \\
(=1 / \mathrm{DREF})\end{array}$ & $\begin{array}{l}\text { All studies } \\
\text { Std. Err. of } Q\end{array}$ & $\begin{array}{l}\text { Excluding Mayak } \\
\text { Estimated } Q\end{array}$ & $\begin{array}{l}\text { Excluding Mayak } \\
\text { Std. Err. of } Q\end{array}$ \\
\hline $\begin{array}{l}\text { Fieller's method } \\
\text { (Fieller 1940) }\end{array}$ & $\begin{array}{l}\text { Meta-analysis with fixed effects (Sutton } \\
\text { and Higgins 2008) }\end{array}$ & 0.3331 & 0.1040 & 0.5390 & 0.2314 \\
\hline Fieller's method & $\begin{array}{l}\text { Meta-analysis with random effects (DerSi- } \\
\text { monian and Laird 1986) }\end{array}$ & 0.3331 & 0.1040 & 0.5390 & 0.2314 \\
\hline $\begin{array}{l}\text { apelta-method (Bevington } \\
\text { and Robinson 2003) }\end{array}$ & $\begin{array}{l}\text { Meta-analysis with fixed effects (Sutton } \\
\text { and Higgins 2008) }\end{array}$ & 0.3331 & 0.1036 & 0.5393 & 0.2306 \\
\hline Delta method & $\begin{array}{l}\text { Meta-analysis with random effects (DerSi- } \\
\text { monian and Laird 1986) }\end{array}$ & 0.3331 & 0.1036 & 0.5393 & 0.2306 \\
\hline Delta method & $\begin{array}{l}\text { Meta-analysis, restricted maximum-likeli- } \\
\text { hood estimator (Viechtbauer 2005) }\end{array}$ & 0.3368 & 0.1073 & 0.6003 & 0.2949 \\
\hline Delta method & $\begin{array}{l}\text { Meta-analysis, DerSimonian-Laird estima- } \\
\text { tor with adjustments (Knapp and Hartung } \\
\text { 2003) }\end{array}$ & 0.3331 & 0.077 & 0.5393 & 0.1695 \\
\hline Delta method & $\begin{array}{l}\text { Meta-analysis, Hunter-Schmidt estimator } \\
\text { (Hunter and Schmidt 2004) }\end{array}$ & 0.3331 & 0.1036 & 0.5393 & 0.2306 \\
\hline Delta method & $\begin{array}{l}\text { Meta-analysis, Hedges estimator (Hedges } \\
\text { and Olkin 1985; Raudenbush 2009) }\end{array}$ & 0.3331 & 0.1036 & 0.5393 & 0.2306 \\
\hline Delta method & $\begin{array}{l}\text { Meta-analysis, Sidik-Jonkman estimator } \\
\text { (Sidik and Jonkman 2005a, b) }\end{array}$ & 0.0166 & 2.7112 & -0.0021 & 2.8980 \\
\hline Delta method & $\begin{array}{l}\text { Meta-analysis, Empirical Bayes estimator } \\
\text { (Morris 1983; Berkey et al. 1995) }\end{array}$ & 0.3331 & 0.1036 & 0.5393 & 0.2306 \\
\hline Delta method & Meta-analysis (Paule and Mandel 1982) & 0.3331 & 0.1036 & 0.5393 & 0.2306 \\
\hline Not required & $\begin{array}{l}\text { York regression (York 2004) (in R-statisti- } \\
\text { cal software) }\end{array}$ & 0.3488 & 0.1096 & 0.5925 & 0.2326 \\
\hline Not required & $\begin{array}{l}\text { York regression, (York 2004) (in Numeri- } \\
\text { cal Recipes) }\end{array}$ & 0.3488 & 0.0901 & 0.5928 & 0.2342 \\
\hline not required & $\begin{array}{l}\text { Orthogonal distance regression (Boggs and } \\
\text { Rogers 1990) (in SciPy) }\end{array}$ & 0.3488 & 0.0860 & 0.5925 & 0.1765 \\
\hline
\end{tabular}

The first column gives the method used to calculate the standard error of the ratio of the excess relative risk (ERR) ratio $\left(q_{i}\right)$ (study/LSS) and the second column gives either the type of meta-analytic method applied or the type of regression

${ }^{a}$ Note (for the third row of results): this is the combination of methods and the result of the meta-estimator of $Q$ as originally reported by Shore et al. (2017)

\section{Discussion}

It has been thoroughly investigated here how different choice of methodology for evaluating dose-rate effects on radiation-related cancer risks may influence the overall results reported in a recent study (Shore et al. 2017). A set of results from the paper by Shore et al. (2017) has been adopted here as a test set of data for applying the many different methods described here that nearly all produced highly consistent results.

During the preparations for the first paper on DREF meta-analysis (Jacob et al. 2009), these potential theoretical issues associated with an unbounded variance of ratios were noted and thoroughly discussed (two statisticians were in this team). This is the reason why both papers (Jacob et al. 2009; Shore et al. 2017) are based on the meta-estimator of $Q=1 / \mathrm{DREF}$, rather than estimating DREF directly. By estimating 1/DREF, one avoids the large and sometimes negative CIs, reported in some low dose-rate radiation epidemiology studies, occurring in the denominator of the risk ratio. By designing the methodology to have the matched LSS model results in the denominator, at least for the all solid cancer models, the CIs are well away from encompassing zero values. Furthermore, rather than basing the LSS risks on matched subsets of the LSS data, which could potentially have very wide CIs encompassing zero, the full LSS models were applied, using re-optimisation of the LSS risk models, so that they were centered at matching attained ages, ages at exposure, sex proportions, etc. The strategy of using the full LSS dataset modeled for the matching age and sex characteristics provides much more stable estimates 
of risks corresponding to the characteristics of each given LDR study than would estimates based on the selections of approximately matched sub-sets of the LSS data. That is, the full-data modeling approach appreciably reduces the uncertainty in the estimated LSS risk estimates, though there might be a minor trade-off in terms of estimation accuracy (i.e., unbiasedness).

The current analysis is intended to address methodological issues and does not imply that the authors recommend a particular value for the DDREF [see Shore et al. (2017) for discussions on DDREF relevant to radiation protection]. Table 2 shows that excluding the Mayak data affects the aggregated risk, but the conclusions relevant to the methodology do not change. It has been demonstrated here that consistent DREF estimators may be obtained using several complementary approaches. Furthermore, it has been shown that if the denominator of the ratio is estimated with sufficiently high precision, then the methods investigated and applied in this paper will produce very similar results.

The criticism involving the recalling of the well-known theoretical point - the ratio of two normal random variables has a theoretically unbounded variance-potentially causing some issues (Little et al. 2021) has been shown to be unfounded when aimed at the DREF published work cited and examined in detail here. However, for the purpose of reporting 95\% CI of ratios for individual studies as done in Table 1 of Little et al. (2021), the use of Fieller-based CIs does make a small difference and more importantly a methodological improvement by removing the potential for critique due to theoretical issues.

The differences in corresponding central estimates in the results of Little et al. (2021) provided in Table 2 are not due to just the application of either the Delta method or the Fieller's method (as their Table 2 caption and heading implies) and this will now be explained in detail. One reads in Little et al. (2021). "The difference made by calculation of central estimates and CI using either Eqs. (3) and (6) or Eqs. (8) and (11) are illustrated with a few examples, using data taken from Table 2 of the paper of Shore et al. (Shore et al. 2017)." Applying "Eqs. (8) and (11)" is just adopting the same methods as used in Shore et al. (2017), i.e., a meta-analysis based on one aggregate of 22 individualstudy ratios where the 22 inverse-variance weightings were obtained using the Delta method. However, applying "Eqs. (3) and (6)" is just performing two meta-analyses, one metaanalysis to aggregate the risks from the 22 low- dose studies and one meta-analysis to aggregate the risks from the 22 matching LSS risks, where, in both meta-analyses, the 22 inverse-variance weightings are obtained directly from the published confidence interval results. In this latter regime, the ratio is formed from the aggregated study risk and the aggregated LSS risk ["Eq. (3)"], and the CI on this one ratio is calculated using the Fieller's method. In the present paper, it was demonstrated practically (Tables 1 and 2) that it is also possible to apply equation "Eq. (8)" with "Eq. (6)" adapted for individual risk ratios, i.e., a meta-analysis based on aggregating 22 individual-study ratios where the 22 inversevariance weightings are obtained using Fieller's methodalthough this possibility appears not to have been considered in Little et al. (2021). The differences in corresponding central estimates of aggregated risks in the results of Little et al. (2021) provided in their Table 2 are due to the different aggregation methods. During the course of the work on the Shore et al. (2017) paper, the authors of that paper discussed aggregating the study risks and aggregating the LSS risk and taking the ratio, but decided against this method, because then the individual one-to-one matching information is lost. In the Shore et al. (2017) and Jacob et al. (2009) studies, a great deal of effort was made (using specially calculated dose conversion factors and re-optimized LSS models) to match each study risk with a specially computed LSS risk, because the individual study risks were for differing:

1. cancer outcome groupings for incidence or mortality: e.g., all solid cancers; all cancers except leukemia, all cancers excluding leukemia and alcohol-related cancers (oropharynx, esophagus, and liver); solid cancers except liver, lung, bone; and all solid cancers except liver;

2. reported doses: e.g., colon dose, skin dose, whole body or $\mathrm{H}_{\mathrm{p}}(10)$ dose, effective dose, stomach dose;

3. gender proportions;

4. ages at exposure;

5. attained ages;

therefore, it was considered very important, then as now, to retain the full matching information in the analysis. The matching, whether by (a) dividing individual study and LSS-matched risks or (b) keeping the risk matching via points in regression analysis, effectively adjusts for all other factors except the dose-rate effect, as far as possible given the study limitations. The present authors therefore: do not consider the use of aggregated study risk and the aggregated LSS risk [i.e., Eq. (3) of Little et al. (2021)] to be a methodological improvement, as the title and main text of Little et al. (2021) states; and recommend against this practice in this specific type of application. The sentence in the results section of Little et al. (2021) "The estimate of $\mathrm{ERR}_{\mathrm{LDR}} / \mathrm{ERR}_{\mathrm{LSS}}$ implied by the delta method for all studies excluding the Mayak data is 0.54 (95\% CI 0.09, 0.99), whereas that implied by the Fieller method is $0.91(0.28$, 1.56) (Table 2),...." is open to potential misinterpretation, because this strong shift in central value from 0.54 to 0.91 is caused by leaving the exact one-to-one matching information out of the analysis, not by the change from using the Delta method to using the Fieller's method. For illustration, on leaving out the one-to-one matching information and 
applying both methods to all studies excluding the Mayak data, one calculates a LDR/LSS ratio of ERRs ["Eq. (3)"] of 0.918 (95\% CI $0.277 ; 1.572$ ) for Fieller's method and 0.918 $(0.273 ; 1.563)$ for the Delta method; which indicates no difference in the central estimate of the ratio and only a slight difference in CI, in contrast to those comparisons given by Little et al. 2021. The contrast with the Little et al.'s results is because they did not use individual one-to-one matching. They reported differences between the Delta-method and the Fieller's method of about $70 \%$ in the estimation of the LDR/ LSS and about a 45\% larger confidence bound for Fieller's method (in their Table 2); whereas, with the individual-study matching used in the present work, there were no differences in the first three decimal places of the ERR ratios and differences in the widths of the ERR-ratio 95\% confidence bounds of only $0.4 \%$.

\section{Conclusion}

It has been demonstrated here, in a practical way, that consistent DREF estimators may be obtained using several complementary approaches. Different choice of methodology for evaluating dose-rate effects on radiation-related cancer risks have been shown not to influence the overall results reported in a recent study (Shore et al. 2017) to any problematic degree. In fact, extremely similar results have been obtained with a wide variety of methods. Based on the results presented here, there is no convincing reason for believing that the previously reported results in Jacob et al. (2009) and Shore et al. (2017) should not stand as well-designed and thorough contributions to research in radiation protection. Furthermore and also based on the results presented here, it is recommended that for radiation protection purposes: meta-estimators of DREF should be calculated keeping the full one-to-one matching information in the analysis (e.g., as in Shore et al. 2017 paper); the Fieller's method for calculating CIs on individual risk ratios is useful for reporting individual ratios; and a regression approach should be considered to be a useful and simple one-step approach.

Acknowledgements This paper makes use of data obtained from the Radiation Effects Research Foundation (RERF), Hiroshima and Nagasaki, Japan. RERF is a public interest incorporated foundation funded by the Japanese Ministry of Health, Labour and Welfare (MHLW) and the U.S. Department of Energy (DOE). The data include information obtained from the Hiroshima City, Hiroshima Prefecture, Nagasaki City, and Nagasaki Prefecture Tumor Registries and the Hiroshima and Nagasaki Tissue Registries. The conclusions in this paper are those of the authors and do not necessarily reflect the scientific judgment of RERF or its funding agencies. The authors would like to thank Dr. J. $\mathrm{R}$. Walsh for calculating the York regression result with the routine from Numerical Recipes and the orthogonal distance regression result with SciPy.
Funding Open Access funding provided by Universität Zürich. No funding was obtained for this work.

\section{Declarations}

Conflicts of interest The authors declare that they have no conflicts of interest to declare.

Open Access This article is licensed under a Creative Commons Attribution 4.0 International License, which permits use, sharing, adaptation, distribution and reproduction in any medium or format, as long as you give appropriate credit to the original author(s) and the source, provide a link to the Creative Commons licence, and indicate if changes were made. The images or other third party material in this article are included in the article's Creative Commons licence, unless indicated otherwise in a credit line to the material. If material is not included in the article's Creative Commons licence and your intended use is not permitted by statutory regulation or exceeds the permitted use, you will need to obtain permission directly from the copyright holder. To view a copy of this licence, visit http://creativecommons.org/licenses/by/4.0/.

\section{References}

Akiba S, Mizuno S (2012) The third analysis of cancer mortality among Japanese nuclear workers, 1991-2001: estimation of excess relative risk per radiation dose. J Radiol Prot 32:73-83

Auvinen A, Pukkala E, Hyvonen H, Hakama M, Rytomaa T (2002) Cancer incidence among Finnish nuclear reactor workers. J Occ Environ Med 44:634-638

Berkey CS, Hoaglin DC, Mosteller F, Colditz GA (1995) A randomeffects regression model for meta-analysis. Stat Med 14:395-411

Bevington PR, Robinson DK (2003) Data reduction and error analysis for the physical sciences, 3rd edn. McGraw-Hill, New York

Beyene J, Moineddin R (2005) Methods for confidence interval estimation of a ratio parameter with application to location quotients. BMC Med Res Methodol 5:32. https://doi.org/10.1186/ 1471-2288-5-32

Boggs PT, Rogers JE (1990) Orthogonal Distance Regression”, in "Statistical analysis of measurement error models and applications: proceedings of the AMS-IMS-SIAM joint summer research conference held June 10-16, 1989. Contemp Math 112:186

Boice JD Jr, Cohen SS, Mumma MT, Ellis ED, Eckerman KF, Leggett RW, Boecker BB, Brill AB, Henderson BE (2011) Updated mortality analysis of radiation workers at Rocketdyne (Atomics International), 1948-2008. Radiat Res 176:244-258

Cardis E, Gilbert E, Carpenter L, Howe G, Kato I, Armstrong B, Beral V, Cowper G, Douglas A et al (1995) Effects of low doses and low dose rates of external ionizing radiation: cancer mortality among nuclear industry workers in three countries. Radiat Res $142: 117-132$

Cardis E, Vrijheid M, Blettner M, Gilbert E, Hakama M, Hill C, Howe G, Kaldor J, Muirhead CR et al (2007) The 15-country collaborative study of cancer risk among radiation workers in the nuclear industry: estimates of radiation-related cancer risks. Radiat Res 167:396-416

DerSimonian R, Kacker R (2007) Random effects model for meta-analysis of clinical trials: an update. Contemp Clin Trials 28:105-114

DerSimonian R, Laird N (1986) Meta-analysis in clinical trials. Control Clin Trials 7:177-188

Engels H, Swaen GM, Slangen J, van Amersvoort L, Holmstock L, Van Mieghem E, Van Regenmortel I, Wambersie A (2005) Radiation exposure and cause specific mortality among nuclear workers in Belgium (1969-1994). Radiat Prot Dosim 117:373-381 
Fieller EC (1940) The biological standardization of insulin. J Roy Stat Soc Suppl 7:1-64

Gulis G (2003) Cancer occurrence among radiation workers at Jaslovske Bohunice nuclear power plant. Central Eur J Public Health 11:91-97

Habib RR, Abdallah SM, Law M, Kaldor J (2005) Mortality rates among nuclear industry workers at Lucas Heights Science and Technology Centre. Auts N Z J Public Health 29:229-237

Hedges LV, Olkin I (1985) Statistical methods for meta-analysis. Academic Press, San Diego

Howe GR, Zablotska LB, Fix JJ, Egel JB (2004) Analysis of the mortality experience among U.S. nuclear power industry workers after chronic low-dose exposure to ionizing radiation. Radiat Res 162:517-526

Hunter JE, Schmidt FL (2004) Methods of meta-analysis: correcting error and bias in research findings, 2nd edn. Sage, Newbury Park

Hwang S-L, Hwang J-S, Yang Y-T, Hsieh WA, Chang T-C, Guo H-R, Tsai M-H, Tang J-L, Lin I-F, Chang WP (2008) Estimates of relative risks for cancers in a population after prolonged low-dose-rate radiation exposure: a follow-up assessment from 1983 to 2005. Radiat Res 170:143-148

ICRP (1991) The 1990 recommendations of the international commission on radiological protection. In: ICRP Publication 60. Pergamon Press, Oxford

ICRP (2007) The 2007 recommendations of the international commission on radiological protection. ICRP publication 103. Ann ICRP 37(2-4):1-332

Jacob P, Rühm W, Walsh L, Blettner M, Hammer G, Zeeb H (2009) Cancer risk of radiation workers larger than expected? Occup Environ Med 66:789-796

Jeong M, Jin Y-W, Yang KH, Ahn Y-O, Cha C-Y (2010) Radiation exposure and cancer incidence in a cohort of nuclear power industry workers in the Republic of Korea, 1992-2005. Radiat Environ Biophys 49:47-55

Kashcheev VV, Chekin SY, Maksioutov MA, Tumanov KA, Kochergina EV, Kashcheeva PV, Shchukina NV, Ivanov VK (2015) Incidence and mortality of solid cancer among emergency workers of the Chernobyl accident: assessment of radiation risks for the follow-up period of 1992-2009. Radiat Environ Biophys 54:13-23

Knapp G, Hartung J (2003) Improved tests for a random effects metaregression with a single covariate. Stat Med 22(17):2693-2710. [PMID: 12939780]

Kreuzer M, Dufey F, Laurier D, Nowak D, Marsh JW, Schnelzer M, Sogl M, Walsh L (2015) Mortality from internal and external radiation exposure in a cohort of male German uranium millers, 1946-2008. Int Arch Occup Environ Health 88:431-441

Little MP, Pawel DJ, Abalo K, Hauptmann M (2021) Methodological improvements to meta-analysis of low dose rate studies and derivation of dose and dose-rate effectiveness factors. Radiat Environ Biophys (Accepted for publication)

McCullagh P, Nelder JA (1989) Generalized linear models, 2nd edn. Chapman and Hall, NewYork

Merzenich H, Hammer GP, Tröltzsch K, Ruecker K, Buncke J, Fehringer F, Blettner M (2014) Mortality risk in a historical cohort of nuclear power plant workers in Germany: results from a second follow-up Radiat. Environ Biophys 53:405-416

Morris CN (1983) Parametric empirical Bayes inference: theory and applications. J Am Stat Assoc 78:47-55

Nair RRK, Rajan B, Akiba S, Jayalekshmi P, Nair MK, Gangadharan P, Koga T, Morishima H, Nakamura S, Sugahara T (2009) Background radiation and cancer incidence in Kerala India-Karunagappally Cohort Study. Health Phys 96:55-66

Paule RC, Mandel J (1982) Consensus values and weighting factors. J Res Natl Bur Stand 87:377-385

Press WH, Teukolsky SA, Vetterling WT, Flannery BP (1992) Numerical recipes: the art of scientific computing, 2nd edn. Cambridge University Press, New York
Raudenbush SW (2009) Analyzing effect sizes: random effects models. In: Cooper H, Hedges LV, Valentine JC (eds) The handbook of research synthesis and meta-analysis, 2nd edn. Russell Sage Foundation, New York, pp 295-315

Richardson DB, Cardis E, Daniels RD, Gillies M, O'Hagan JA, Hamra GB, Haylock R, Laurier D, Leuraud K et al (2015) Risk of cancer from occcupational exposure to ionising radiation: retrospective cohort study of workers in France, the United Kingdom, and the United States (INWORKS). Br Med J 351:5359

Rühm W, Woloschak GE, Shore RE, Azizova TV, Grosche B, Niwa O, Akiba S, Ono T, Suzuki K et al (2015) Dose and dose rate effects of ionizing radiation: a discussion in the light of radiological protection. Radiat Environ Biophys 54:379-401

Rühm W, Azizova TV, Bouffler SD, Little MP, Shore RE, Walsh L, Woloschak GE (2016) Dose rate effects in radiation biology and radiation protection. Ann ICRP 45(1 Suppl):262-279

Schonfeld SJ, Krestinina LY, Epifanova S, Degteva MO, Akleyev AV, Preston DL (2013) Solid cancer mortality in the Techa River cohort (1950-2007). Radiat Res 179:183-189

Shore R, Walsh L, Azizova T, Rühm W (2017) Risk of solid cancer in low dose-rate radiation epidemiological studies and the dose-rate effectiveness factor. Int J Radiat Biol 93:1064-1078

Sidik K, Jonkman JN (2005a) A note on variance estimation in random effects meta-regression. J Biopharma Stat 15(5):823-838

Sidik K, Jonkman JN (2005b) Simple heterogeneity variance estimation for meta-analysis. J Roy Stat Soc C 54(2):367-384

Sokolnikov ME, Preston D, Gilbert E, Schonfeld S, Koshurnikova NA (2015) Radiation effects on mortality from solid cancers other than lung, liver, and bone cancer in the Mayak worker cohort: 1948-2008. PLoS ONE 10:e0117784

Stuart A, Ord K (1994) Kendall's advanced theory of statistics, vol 1, 6th edn. Hodder Arnold, London

Sutton AJ, Higgins JPT (2008) Recent developments in meta-analysis. Stat Med 27:625-650

Tao Z, Akiba S, Zha Y, Sun Q, Zou J, Li J, Liu Y, Yuan Y, Tokonami $S$ et al (2012) Cancer and non-cancer mortality among inhabitants in the high background radiation area of Yangjiang, China (1979-1998). Health Phys 102:173-181

Viechtbauer W (2005) Bias and efficiency of meta-analytic variance estimators in the random-effects model. J Educ Behav Stat 30(3):261-293

Viechtbauer W (2010) Conducting meta-analyses in R with the metafor package. J Stat Softw 36:3

Virtanen P, Gommers R, Oliphant TE, Haberland M, Reddy T, Cournapeau D, Burovski E, Peterson P, Weckesser W et al (2020) SciPy 1.0: fundamental algorithms for scientfic computng in python. Nat Methods 17(3):261-272

York D (1966) Least-squares fitting of a straight line. Can J Phys 44(5):1079-1086

York D (1968) Least squares fitting of a straight line with correlated errors. Earth Planet Sci Lett 5:320-324

York D et al (2004) Unified equations for the slope, intercept, and standard errors of the best straight line. Am J Phys 72:367-375

Zablotska LB, Lane RS, Frost SE (2013) Mortality (1950-1999) and cancer incidence (1969-1999) of workers in the Port Hope cohort study exposed to a unique combination of radium, uranium and gamma-ray doses. BMJ Open 3:e002159

Zablotska LB, Lane RSD, Thompson PA (2014) A reanalysis of cancer mortality in Canadian nuclear workers (1956-1994) based on revised exposure and cohort data. Br J Cancer 110:214-223

Publisher's Note Springer Nature remains neutral with regard to jurisdictional claims in published maps and institutional affiliations. 